\title{
Diel changes in humpback whale Megaptera novaeangliae feeding behavior in response to sand lance Ammodytes spp. behavior and distribution
}

\author{
Ari S. Friedlaender ${ }^{1,2, *}$, E. L. Hazen ${ }^{1,2}$, D. P. Nowacek ${ }^{1,3}$, P. N. Halpin ${ }^{1,2}$, C. Ware ${ }^{4}$, \\ M. T. Weinrich ${ }^{5}$, T. Hurst ${ }^{6}$, D. Wiley ${ }^{7}$ \\ ${ }^{1}$ Duke University Marine Laboratory, 135 Pivers Island Road, Beaufort, North Carolina 28516, USA \\ ${ }^{2}$ Marine Geospatial Ecology Lab, Nicholas School of Environment and Earth Sciences, Duke University, Durham, \\ North Carolina 27708, USA \\ ${ }^{3}$ Pratt School of Engineering, Duke University, Durham, North Carolina 27708, USA \\ ${ }^{4}$ University of New Hampshire, 24 Colovos Road, Durham, New Hampshire 03824, USA \\ ${ }^{5}$ The Whale Center of New England, 24 Harbor Loop, Gloucester, Massachusetts 01931, USA \\ ${ }^{6}$ Woods Hole Oceanographic Institution, Woods Hole, Massachusetts 02543, USA \\ ${ }^{7}$ Stellwagen Bank National Marine Sanctuary, 175 Edward Foster Road, Scituate, Massachusetts 02066, USA
}

\begin{abstract}
Humpback whales Megaptera novaeangliae have adopted unique feeding strategies to take advantage of behavioral changes in their prey. However, logistical constraints have largely limited ecological analyses of these interactions. Our objectives were to (1) link humpback whale feeding behaviors to concurrent measurements of prey using scientific echo-sounders, and (2) quantify how sand lance behavior influences the feeding behaviors and foraging ecology of humpback whales. To measure, in fine detail, the 3-dimensional orientation and movement patterns of humpback whales underwater, we used a multi-sensor tag attached via suction cups (DTAG). We tested the specific hypothesis that the diel movement patterns of sand lance between bottom substrate and the water column correlates to changes between surface and bottom feeding strategies of humpback whales on Stellwagen Bank, MA. We collected over $96 \mathrm{~h}$ of both day- and nighttime data from 15 whales in 2006, and recorded 393 surface and 230 bottom feeding events. Individual whales exhibit both surface and bottom feeding behaviors, switching from one to the other in relation to changing light and prey conditions. Surface feeding behaviors were individually variable in their constitution but ubiquitously biased towards daylight hours, when prey was most abundant in the upper portion of the water column. Bottom feeding behavior occurred largely at night, coincident with when sand lance descend to seek refuge in the substrate. Our data provide novel insights into the behavioral ecology of humpback whales and their prey, indicating significant diel patterns in foraging behaviors concurrent with changes in prey behavior.
\end{abstract}

KEY WORDS: Humpback whales $\cdot$ Sand lance $\cdot$ Diel feeding $\cdot$ Predator-prey interactions

\section{INTRODUCTION}

In pelagic marine ecosystems, direct and quantitative research on predator-prey interactions has largely been limited due to difficulties in concurrently and accurately measuring the behaviors of both predators and prey at meaningful ecological scales. While baleen whale feeding behavior and foraging ecology is largely known from surface observations, there is an increasing body of evidence describing how whales feed at depth (Croll et al. 2001, Acevedo-Gutiérrez et al. 2002, Witteveen et al. 2008). Research addressing relationships between baleen whales and their prey has typically fallen into several categories: coarse mea- 
surements of prey abundance and visual surveys of cetacean distribution sampled over broad areas (e.g. Payne et al. 1986, Weinrich et al. 1997, Friedlaender et al. 2006), circumstantial and qualitative records of the underwater behavior of both whales and prey from echo sounders (e.g. Dolphin 1987), quantitative measurements of prey using fisheries acoustics and presumptive foraging behaviors of whales based on time and depth records of tagged whales (e.g. Croll et al. 2001), and more recently, quantitative measures of foraging behaviors of whales from multiple sensors on attached tags compared with general and relative measures of zooplankton from scientific echo sounders (e.g. Goldbogen et al. 2008).

Recent advances in sensor technology and miniaturization now allow for unprecedented recording of the underwater movements and behaviors of individual whales (e.g. Nowacek et al. 2004, Johnson \& Tyack 2003, Ware et al. 2006). This technology has the ability to measure the underwater orientation of whales and track changes in their behavior over time, which, in some cases, can be corroborated with observations of whales at the surface. Traditional fisheries acoustics provide an accurate means for detecting, quantifying, and continuously documenting changes in the distribution, abundance, and behavior of prey throughout the water column (Misund et al. 1995, Simard \& Lavoie 1999). Thus, the potential now exists to combine previously unattainable information on the behaviors of cetaceans and their prey in a way that allows for hypothesis-driven experimental research on how the behavior of individual cetaceans relates to that of their prey.

To support their large body size, baleen whales require large amounts of prey distributed as localized dense prey patches (Dolphin 1987, Piatt \& Metheven 1992, Friedlaender et al. 2006, Witteveen et al. 2008). As predators, cetaceans display a variety of foraging strategies and feeding behaviors, many of which are locally unique and specialized for specific prey (Simila \& Ugarte 1993). Some of this specialty is manifested as unique behaviors to corral or concentrate prey (e.g. humpback whales Megaptera novaeangliae, Jurasz \& Jurasz 1979, Hain et al. 1982, Weinrich et al. 1992; fin whales Balaenoptera physalus, Goldbogen et al. 2006). Plasticity in feeding behaviors, which may be learned through several mechanisms (see Whiten \& Ham 1992 for a review), is important to allow animals such as baleen whales to adapt to changing prey and environmental conditions.

One area where humpback whale foraging behavior has been studied is around Stellwagen Bank, MA, USA. Humpback whales use this area within their feeding grounds in the Gulf of Maine from April through December, and sand lance Ammodytes spp. are their primary prey (Overholtz \& Nicholas 1979, Hain et al. 1982). Based on visual observations, hump- back whales (here and elsewhere) are known to produce bubble nets and clouds presumably to aggregate prey and make feeding more efficient (Jurasz \& Jurasz 1979, Hain et al. 1982, Weinrich et al. 1992). It has also been found that, in combination with other potential prey, sand lance abundance in this region has a dominant effect on the regional distribution and relative abundance of humpback whales (Payne et al. 1986, 1990, Kenney et al. 1996, Weinrich et al. 1997).

Over the past $30 \mathrm{yr}$, natural and induced ecosystem perturbations (including effects of overfishing) have led to changes in the dominant ichthyofauna on Stellwagen Bank, and in many cases throughout the Gulf of Maine, from herring to sand lance (Fogarty et al. 1991). Behavioral studies and laboratory research have shown that sand lance burrow into sandy substrate at night and during times of relatively low density, and migrate vertically during daylight hours forming dense schools (Winslade 1974, Meyer et al. 1979). Concurrent to the increase in sand lance dominance in the area, Hain et al. (1995) described apparent bottom feeding on sand lance by humpback whales on Stellwagen Bank based on the presence of rostral abrasions and scars and an absence of observed surface feeding observations during the same periods.

Our objectives in this study were to (1) link known and presumed humpback whale feeding behaviors to spatially and temporally concurrent measurements of prey distribution and abundance throughout the water column using scientific echo-sounders, and (2) explore and quantify how the behavior of sand lance influences the choice and timing of unique feeding behaviors and the foraging ecology of humpback whales. To measure, in fine detail, the 3-dimensional orientation and movement patterns of humpback whales underwater, we used a multi-sensor tag attached via suction cups (DTAG, Johnson \& Tyack 2003). We tested the specific hypothesis that the diel movement patterns of sand lance between bottom substrate and the water column correlates to changes between surface and bottom feeding strategies of humpback whales on Stellwagen Bank.

\section{MATERIALS AND METHODS}

Data collection. Whale tagging and acoustic prey surveys were conducted from the NOAA RV 'Nancy Foster' in the waters of the Stellwagen Bank National Marine Sanctuary, MA, from 6 to 20 July 2006. Acoustic surveys were conducted by continuously towing 38 and $120 \mathrm{kHz}$ Simrad EK60 echosounders. Acoustic samples were collected 10 times $\mathrm{s}^{-1}$ with pulse widths of 512 and $256 \mathrm{~ms}$ respectively. Each echosounder was calibrated using methods described 
in Demer et al. (1999). Prey data were recorded as scattering volume $\left(\mathrm{s}_{\mathrm{v}}\right)$ in decibels and integrated into areal backscatter $\left(\mathrm{s}_{\mathrm{A}}\right)$ for analysis.

When humpback whales were located, a rigidhulled inflatable boat was deployed to conduct photoidentification, tagging, and behavioral observations (focal follows). Each whale was photographed and later identified using a central catalog of humpback whales maintained by the Whale Center of New England, Gloucester, MA. Next, whales were approached and outfitted with a DTAG. The DTAG (Johnson \& Tyack 2003) is a small, lightweight, pressure tolerant and waterproof tag non-invasively placed on a whale using a carbon-fiber pole and attached via 4 silicon suction cups. These tags have successfully been deployed on a number of baleen and toothed whales (Nowacek et al. 2004, Woodward \& Winn 2006). The DTAG is equipped with a pressure sensor and 3-axis magnetometer and accelerometers that measure depth, heading, pitch, and roll, 5 times $\mathrm{s}^{-1}$. The tag is also equipped with a VHF antenna and unique frequency that allows radio-tracking of animals when they are at the surface and re-location of the tag upon release. Data is archived on the tag during deployment and later downloaded through an infrared port for calibration and analysis.

Focal follows were conducted from inflatable boats on tagged whales during daylight hours. Data collected at each surfacing included time, GPS location, group size and composition, behavior of focal and other associated individuals (as defined in Whitehead 1983), and environmental conditions. During night hours, behavioral observations were impossible, and the RV 'Nancy Foster' maintained proximity to the tagged whale by VHF radio contact.

In order to quantify the spatial distribution and abundance of prey around both feeding and non-feeding whales we employed an iterative survey design customized for each behavioral state. When whales were traveling, the boat followed approximately $500 \mathrm{~m}$ behind in a saw-tooth pattern with $\sim 1.8 \mathrm{~km}$ transects to measure prey after it had been passed by the whales. When the tagged whale was either surface feeding or resting (non-feeding and non-traveling), we designed an expanding box (the smallest being $1 \mathrm{~km}^{2}$ ) centered within $200 \mathrm{~m}$ of the whale to measure prey across multiple spatial scales. Prey species were identified from visual observations at the surface or from photographs taken of whales as they broke the surface with gaped mouths during surface feeding and prey were visible trying to escape.

Acoustic data were analyzed using Sonardata's Echoview ${ }^{\circledR}$ software version 4.2. To exclude high intensity bottom reflections, the sounder-detected bottom was manually inspected for errors and was raised by $0.5 \mathrm{~m}$. Each sonar ping of the entire water column was divided in half by depth and vertically integrated to obtain an areal backscatter value $\left(\mathrm{s}_{\mathrm{A}}\right.$ in $\mathrm{m}^{2}$ nautical mile $\mathrm{e}^{-2}$ ) for the top and bottom half of the water column. These upper and lower water column data were subsequently imported into a geographic information system (ArcGIS 9.2) and interpolated into a regular grid of $50 \mathrm{~m}$ cells using semivariance analysis and a global kriging function to account for spatial autocorrelation in the data and to examine estimated interpolation error. We then sampled the estimated density and distribution of prey within each cell spatially corresponding with an identified whale behavioral event (i.e. surface or bottom foraging).

Analysis. We used Trackplot (Ware et al. 2006) to visualize and analyze the movement patterns of whales from DTAG sensors (Fig. 1). The depth, pitch, roll, and heading data were geo-referenced by time along the track or anchored to GPS locations collected during surfacing events from the focal follows. Trackplot is a visualization tool that represents the continuous movement and orientation of the whale as a ribbon surface. Behaviors such as rolling are indicated by twists around the along-track ribbon (Ware et al. 2006). The ribbon uses a sampling rate of $1 \mathrm{~Hz}$ and includes not only pitch, roll, and heading, but also depth and time. To verify surface feeding behaviors in the dive record, we examined the ribbon plots at times when behavioral sequencing indicated a surface feeding event performed by the tagged whale. We were able to positively match the ribbon plot with observed feeding events in 97 out of 100 randomly sampled surfacing events. We then examined the dive records for every whale and recorded the time, duration, and maximum depth for each dive preceding the surface feeding event. We calculated the mean dive depth as the halfway point between the surface and maximum dive depth, regardless of its relation to the ocean depth at the dive location. Surface feeding events were found to include one or more underwater loops or circles on the proceeding dive, resulting in a surfacing in close proximity to the dive location or within the area of the loop(s) (Fig. 1A,B). To determine the mean depth and duration of each type of feeding event, surface feeding events were considered from the initiation of the dive in which the bubble-net/circle was made through the next surfacing when feeding was witnessed.

A bottom feeding event was defined using the hypothesis presented by Hain et al. (1995) that humpback whales bottom feed on Stellwagen Bank by rolling on their side and 'brushing' the bottom, typically using the right side of their mouth. Ware et al. (2006) use this information to code the ribbon plots in Trackplot to highlight any off axis roll of $>40^{\circ}$. Thus, we similarly processed the dive records, recording the 

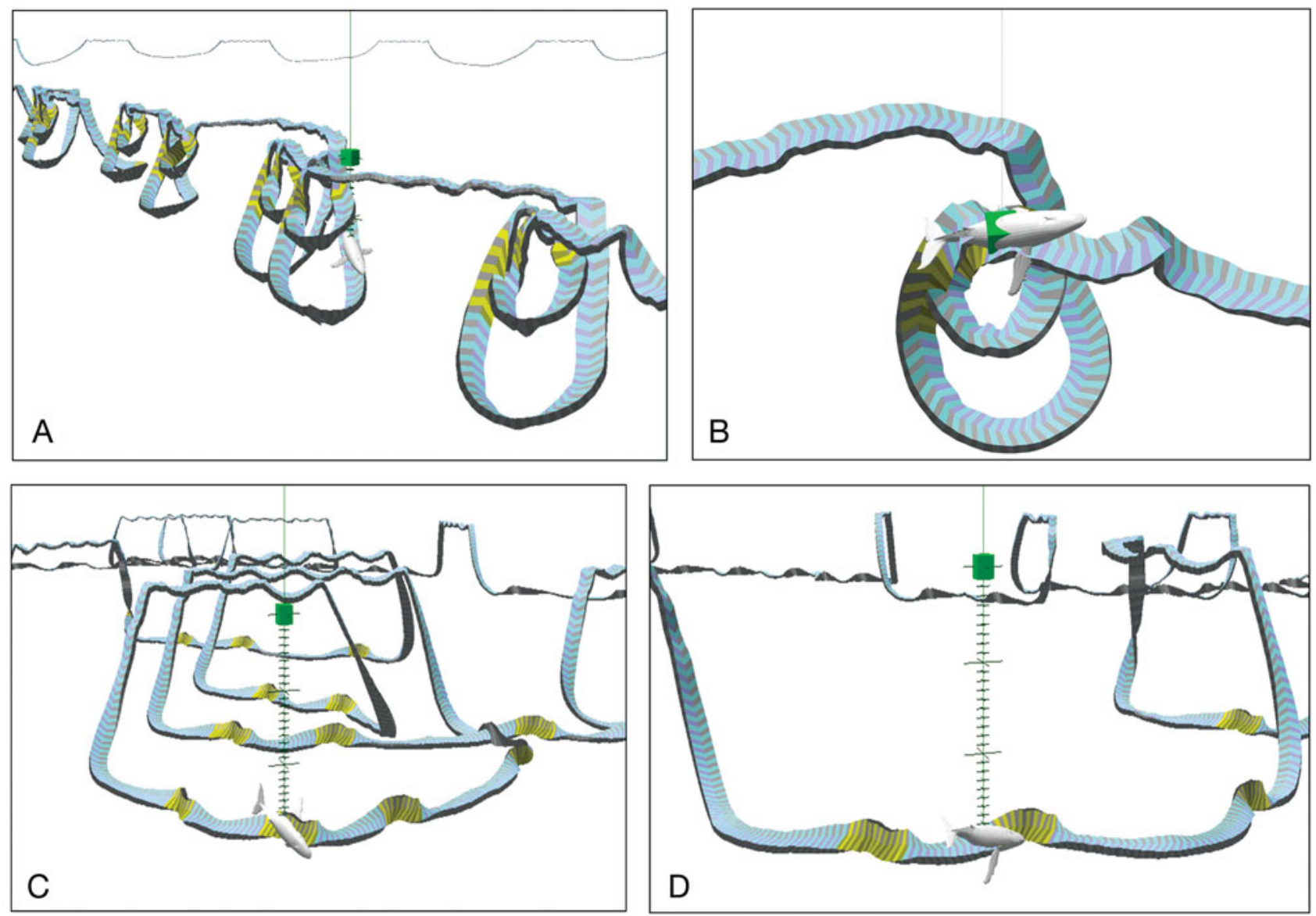

Fig. 1. Megaptera novaeangliae. Ribbon plots of humpback whale foraging behaviors made in TrackPlot using Digital acoustic recording tag (DTAG) data (whale mn192a). For reference the ribbon is $4 \mathrm{~m}$ wide and the whale model is approximately to scale. The small tick marks on the vertical line attached to the whale model represent $1 \mathrm{~m}$ depth below the surface (green square). (A,B) Repeated looping behaviors associated with surface feeding and ending at the surface. $(C, D)$ Repeated side rolls at the bottom. The track is colored yellow where the roll angle exceeded $40^{\circ}$

time, duration, and depth of apparent bottom feeding behaviors as indicated by repeated rolling behavior at or near the bottom (Fig. 1C,D). For bottom feeding events we included the duration and depth when the whale reached the bottom of its dive and initiated parallel travel until it began its ascent.

To minimize sampling bias, we standardized the number of feeding events per hour by the number of whales tagged during each hour of the day. In order to determine whether diel patterns were apparent in humpback whale foraging behaviors, we compared the distribution of both surface and bottom feeding events by hour across a $24 \mathrm{~h}$ period. We used local sunrise and sunset times retrieved from NOAA's marine weather database (http://www.weather.gov/ view/states.php? state=MA) to define whether a surfacing occurred during day or night.

In order to test the hypotheses that different feeding behaviors are related to changes in prey behavior, we compared whale behavior and prey distribution and abundance in the upper and lower $50 \%$ of the water column regardless of total depth. For each of the 3 behavioral categories (surface feeding, bottom feeding, and non-feeding), we used 2-tailed $t$-tests (Zar 1996) to compare the amount of prey in the upper and lower halves of the water column. We compared the prey abundance associated with each whale behavioral state by dive for the upper and lower $50 \%$ of the water column using non-parametric Wilcoxon/ Kruskal-Wallis rank-sum tests (Zar 1996). Because of our sample sizes, we treated each feeding event as an independent measurement, similar to the approach used by Goldbogen et al. (2006).

\section{RESULTS}

Between 7 and 19 July 2006, 15 humpback whales were tagged, resulting in 95.3 hours of sensor measurements. Tag deployments ranged from $0.6 \mathrm{~h}$ to 
$21.4 \mathrm{~h}$, with a mean $\pm \mathrm{SD}$ of $6.4 \pm 6.7 \mathrm{~h}$. We collected $66.1 \mathrm{~h}$ of daytime and $29.2 \mathrm{~h}$ of nighttime tag measurements. The discrepancy in tag data between day and night resulted from logistic constraints of collecting as much data during nighttime hours. Tags were typically deployed between 07:00 to 10:00 and 13:40 to 18:00 h. Details on the timing, duration, and identification of each animal for each DTAG deployment are shown in Table 1. DTAGs were deployed on a total of $7 d_{\text {; }}$ on 6 of these we had tags deployed on multiple animals.

Using measurements from tags, we recorded 393 surfacing feeding events; 372 occurred during daylight hours and 1 within $1 \mathrm{~h}$ of sunset or sunrise (sunrise occurred between 05:15 and 05:24 h, and sunset between 20:16 and 20:24 h). Surface feeding events were characterized by individually variable patterns, including single, double, and triple underwater loops prior to breaking the surface (see Fig. 1A,B). We recorded 230 presumed bottom feeding events; 199 occurred during night hours and 31 between sunrise and sunset. Presumed bottom feeding dives were consistent with respect to their overall shape, directionality, and the manner in which the whales habitually rolled on their right side (Fig. 1C,D). The depth at which these behaviors occurred was in close proximity to the overall bathy-
Table 1. Megaptera novaeangliae. Digital acoustic recording tag (DTAG) deployment information including date (given as mo/d/yr), ID, individual whale tagged, tag-on time, and deployment duration

\begin{tabular}{|lcccc|}
\hline ID & Animal & Date & Tag-on time & Time on animal $(\mathrm{h})$ \\
\hline mn188a & Underline & $7 / 7 / 06$ & $9: 05: 28$ & 3.57 \\
mn188b & Ventisca & $7 / 7 / 06$ & $10: 10: 25$ & 10.65 \\
mn189a & Thalassa & $7 / 8 / 06$ & $9: 26: 43$ & 1.38 \\
mn189b & Division & $7 / 8 / 06$ & $13: 40: 38$ & 0.62 \\
mn189c & Zipper & $7 / 8 / 06$ & $15: 19: 17$ & 3.07 \\
mn192a & Division & $7 / 11 / 06$ & $8: 13: 00$ & 21.3 \\
mn192b & Nile & $7 / 11 / 06$ & $8: 20: 49$ & 2.44 \\
mn195a & Fulcrum & $7 / 14 / 06$ & $14: 17: 19$ & 10.13 \\
mn195b & Epee & $7 / 14 / 06$ & $15: 33: 40$ & 3.32 \\
mn196a & Dyad & $7 / 15 / 06$ & $8: 51: 16$ & 21.4 \\
mn196b & Ursa & $7 / 15 / 06$ & $10: 01: 04$ & 2.68 \\
mn197a & Ivee & $7 / 16 / 06$ & $18: 04: 11$ & 3.44 \\
mn200a & Roswell & $7 / 19 / 06$ & $7: 03: 42$ & 4 \\
mn200b & Glo-stick & $7 / 19 / 06$ & $7: 30: 46$ & 1.47 \\
mn200c & Bilbo & $7 / 19 / 06$ & $16: 56: 02$ & 5.8 \\
& & & Total tag time & $\mathbf{9 5 . 2 7}$ \\
& & & Day & $\mathbf{6 6 . 1 1}$ \\
& & & Night & $\mathbf{2 9 . 1 6}$ \\
\hline
\end{tabular}

metric depth, approximately $90 \%$ of the total depth. The only times when both types of foraging behaviors were observed was between 04:00 and 05:00 $\mathrm{h}$, and between 18:00 and 21:00 h, essentially crepuscular periods (Fig. 2). Full overnight tag deployments were made on 2 whales (mn192a and mn196a, Table 1). In both cases, each whale began surface feeding during daylight hours, switched to bottom feeding during the night, and returned to surface feeding the next morning (Fig 3).

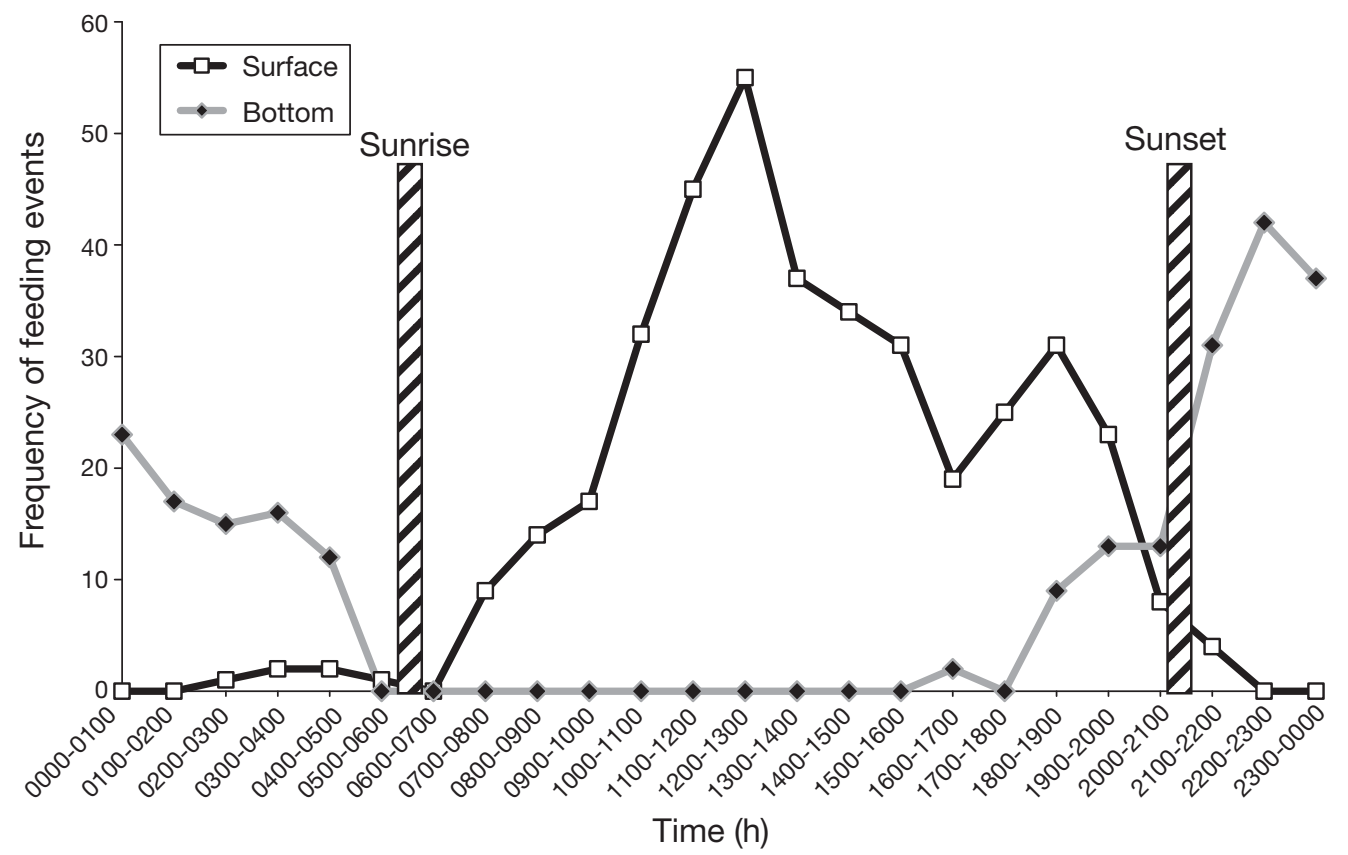

Fig. 2. Megaptera novaeangliae. Timing and frequency of surface and bottom feeding events measured during each hour from all tagged humpback whales across a $24 \mathrm{~h}$ axis. Local sunrise and sunset are shown as hatched bars for reference 
When corrected for sampling effort during daylight hours, we recorded a mean of 5.2 surface feeding events $\mathrm{h}^{-1}$, compared to $0.4 \mathrm{~h}^{-1}$ at night. Conversely, we recorded a mean of 9.0 bottom feeding events $\mathrm{h}^{-1}$ at night, and $1.0 \mathrm{~h}^{-1}$ during daytime (Fig. 4). Bottom foraging began to increase just before sunset and increased in frequency, peaking between 22:00 and 00:00 $\mathrm{h}$, then remained relatively stable until 05:00 h, after which it ceased completely (Fig. 2). For the 2 whales mn192a and mn196a, surface feeding began before sunrise, at 05:00 h, and increased through the morning hours before ceasing by 11:00 h (Fig. 3). We do not have complete tag data from 06:00 to 09:00 h, but the trends in increasing surface feeding activity appear to be consistent between whales. After this point, surface feeding peaked between 09:00 and 10:00 h. During daylight
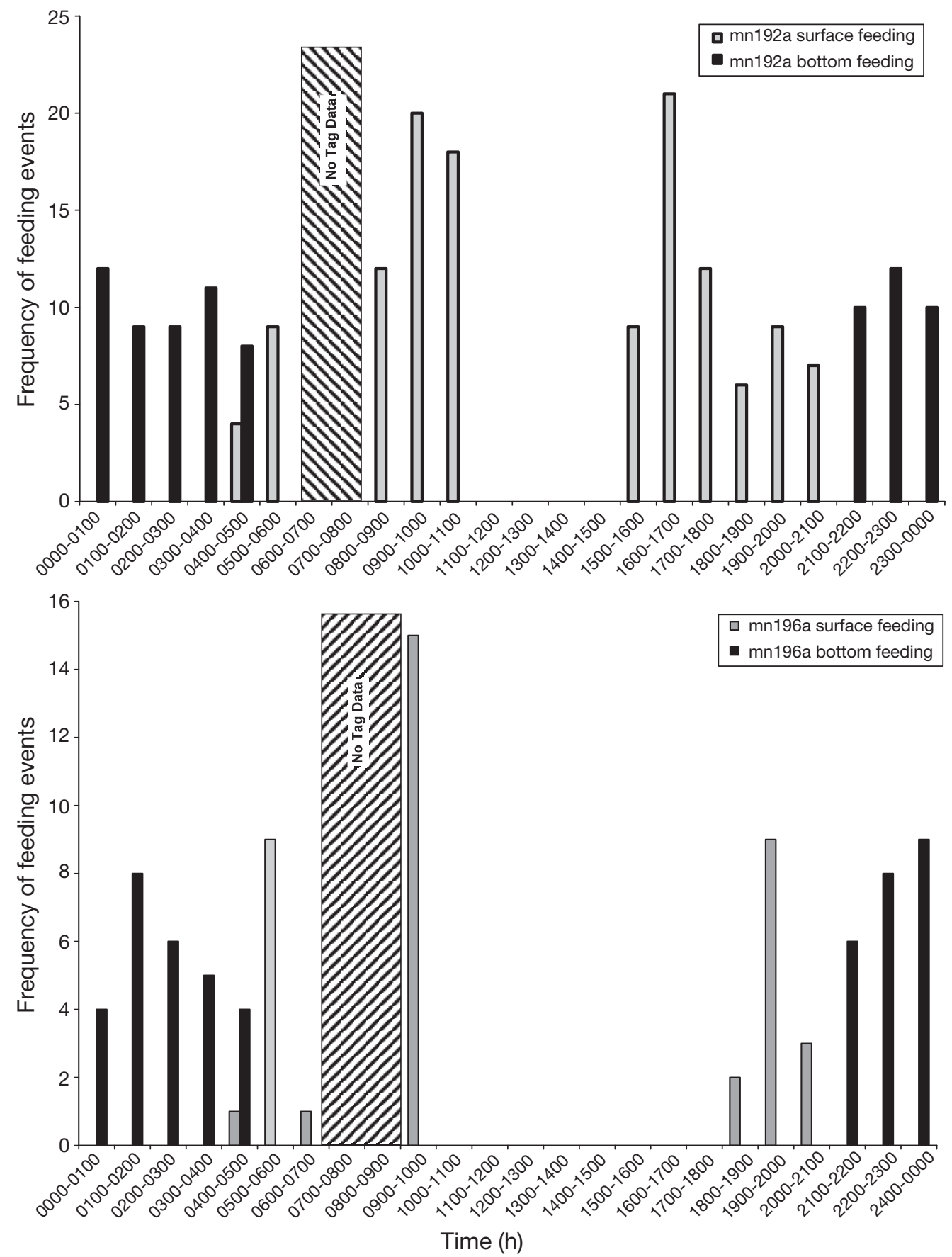

Fig. 3. Megaptera novaeangliae. Frequency distributions of measured surface and apparent bottom feeding events for 2 humpback whales (mn192a, mn196a). Hatched bars indicate the time over a $24 \mathrm{~h}$ period when the whale was not tagged 


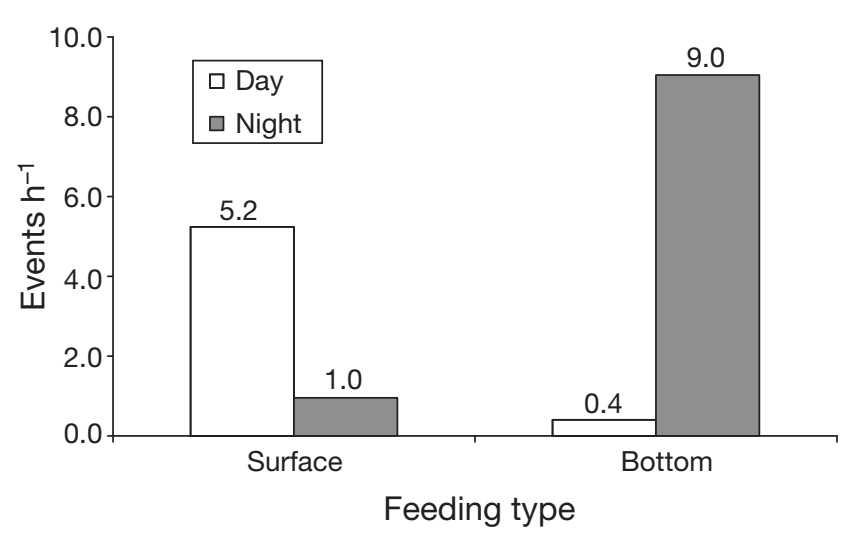

Fig. 4. Megaptera novaeangliae. Frequency (events $\mathrm{h}^{-1}$ ) of measured surface and presumed bottom feeding events for all tagged whales. Comparisons are made between surface and bottom feeding during both day and night, respectively

hours, surface feeding frequency maintained a bimodal trend, peaking between 09:00 and 10:00 h, declining until 14:00 to $15: 00 \mathrm{~h}$, increasing again until 16:00 to $17: 00 \mathrm{~h}$, and then declining and ceasing after sunset (Fig. 2). Surface feeding dives had a mean duration of $95 \pm 46 \mathrm{~s}$ (range: 12 to $318 \mathrm{~s}$ ) at a mean depth of $20.0 \pm 7.0 \mathrm{~m}$ (range: 2.5 to $49.5 \mathrm{~m}$ ). Bottom feeding dives had a mean duration of $204 \pm 87.5 \mathrm{~s}$ (range: 18 to $465 \mathrm{~s}$ ) at an average depth of $31 \pm 2.7 \mathrm{~m}$ (range: 26 to $43 \mathrm{~m}$ ).

Vertically integrated biomass $\left(\mathrm{s}_{\mathrm{A}}\right)$ ranged between 0 and $29228 \mathrm{~m}^{2} \mathrm{n}$ mile $^{-2}$, averaging $96.5 \mathrm{~m}^{2} \mathrm{n} \mathrm{mile} \mathrm{e}^{-2}$ in the top half of the water column, and $123.3 \mathrm{~m}^{2} \mathrm{n}$ mile $^{-2}$ in the bottom half of the water column across the entire study area. When comparing prey in the upper half of the water column across feeding and non-feeding activities, significantly more prey was found during surface feeding dives than during both bottom and non-feeding dives (chi-squared $=49.31, \mathrm{df}=2, \mathrm{p}<$ 0.001 , Fig. 5, Table 2). Conversely, there was no difference in the amount of prey found in the bottom $50 \%$ of the water column during surface, bottom, or non-feeding dives (chi-squared $=0.54, \mathrm{df}=2, \mathrm{p}=0.76$, Fig. 5, Table 2). When comparing prey abundance vertically during surface feeding events, significantly more was measured in the upper than the lower half of the water column $(\mathrm{p}=0.0002, t$-ratio $=3.59, \mathrm{df}=784)$. During bottom feeding events, the presumed prey was significantly more abundant in the bottom half than in the top half of the water column $(\mathrm{p}=0.01, t$-ratio $=-2.28$, $\mathrm{df}=458)$. There was a marginally significant difference in the amount of prey between the upper and lower half of the water column found during non-feeding events $(\mathrm{p}=0.04, t$-ratio $=-1.81, \mathrm{df}=534)$.

\section{DISCUSSION}

Previous research on baleen whale behavior has been limited largely by the ability to measure and reproduce fine-scale animal movements along only 2 dimensions and planes, as well as by limitations on describing sub-surface activity and behaviors. The combination of newly available sensor technology (DTAG) and analytical tools for the resulting data (Trackplot), produce a novel, accurate, and highly inte-

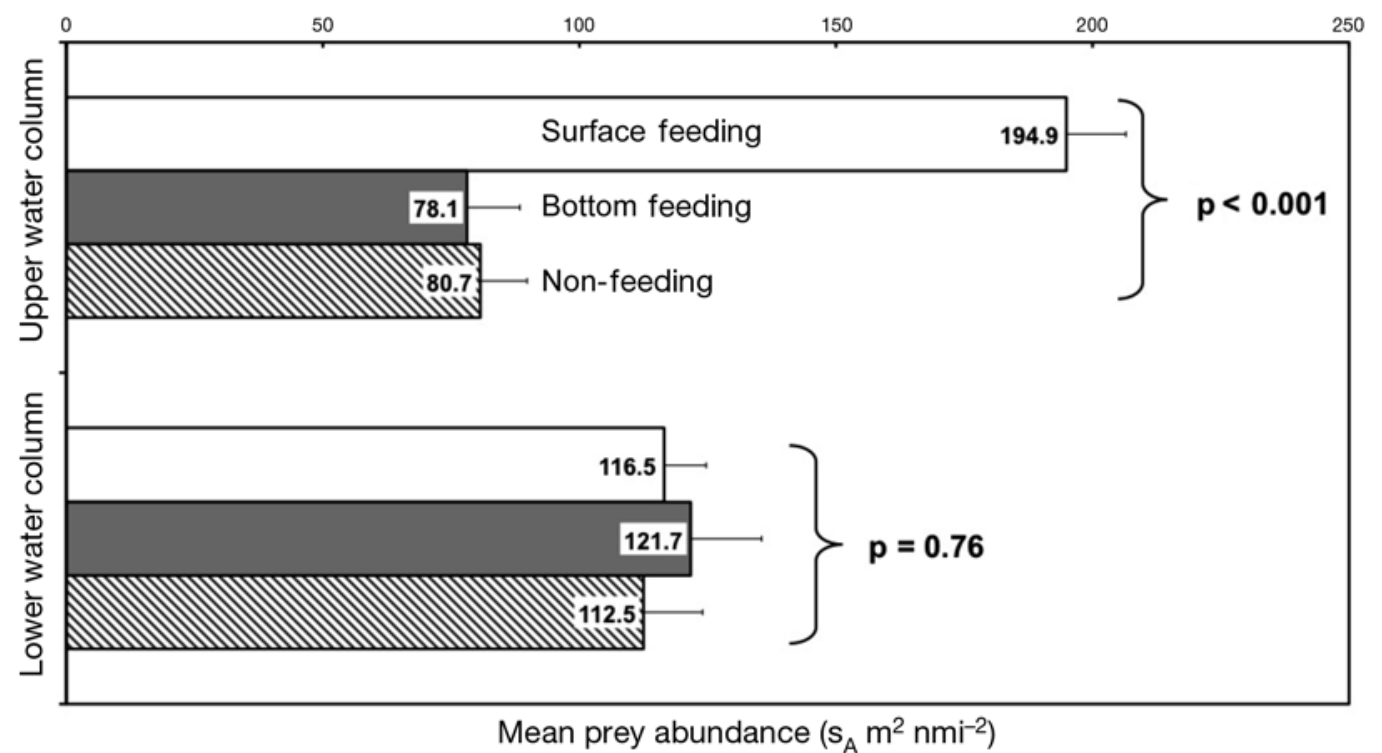

Fig. 5. Megaptera novaeangliae. Mean prey abundance in both the upper and lower halves of the water column during surface, bottom, and non-feeding events. Mean values (+SE) are shown inside the bars, while p-values from Wilcoxon/Kruskal-Wallis rank-sum tests are shown outside of the bars. Tests were run using the upper and lower water column separately as predictor variables and mean values for surface, bottom, and non-feeding as response variables 
Table 2. Megaptera novaeangliae. Analyses of relationship between humpback whale foraging and prey abundance. Columns represent Wilcoxon/Kruskal-Wallis rank-sum tests comparing measured mean prey abundance throughout the water column to humpback whale behaviors. Rows represent $t$-tests comparing measured prey abundance in upper to that in lower portions of the water column during surface, bottom and non-feeding events

\begin{tabular}{|c|c|c|c|c|}
\hline & Upper water column & Lower water column & $\mathrm{p}$-value & Test statistics \\
\hline Surface feeding & 194.9 & 116.5 & 0.0002 & $t=3.59, \mathrm{df}=784$ \\
\hline Bottom feeding & 78.1 & 121.7 & 0.01 & $t=-2.28, \mathrm{df}=458$ \\
\hline Non-feeding & 80.7 & 112.5 & 0.04 & $t=-1.81, \mathrm{df}=534$ \\
\hline p-value & $<0.001$ & 0.76 & & \\
\hline Test statistics & Chi-sq $=49.31, \mathrm{df}=2$ & Chi-sq $=0.54, \mathrm{df}=2$ & & \\
\hline
\end{tabular}

grative means for measuring the underwater behaviors of cetaceans. We have identified and quantified consistently patterned feeding behaviors, and related these to a suite of environmental variables and prey metrics in this and companion studies (e.g. Ware et al. 2006, Stimpert et al. 2007, Hazen et al. 2009, this Theme Section) to test specific hypotheses regarding feeding mechanics and prey behavior. We have used proven fisheries acoustic methods in a dynamic way to link the behavior and movement patterns of prey with those of their predators in the ecological context of predatorprey interaction.

Our results indicate pronounced diel differences between surface and bottom feeding behaviors in humpback whales that correlate with vertical changes in the distribution and abundance of their main prey on Stellwagen Bank. Previous research provides evidence that diel diving patterns in shallow-diving cetaceans are generally related to feeding (Panigada et al. 1999) and are likely correlated with food availability (Aoki et al. 2007). Surface feeding by humpback whales during this study occurred almost exclusively during daylight hours and crepuscular times with some remnant light, while bottom-feeding occurred virtually only during night hours with little or no available light.

The behavior of sand lance appears to have an important effect on the foraging behavior and ecology of humpback whales. Sand lance exhibit pronounced diel movement patterns, becoming active in the water column during daylight hours, dependent on prey availability (Winslade 1974), and descending to specific bottom substrates at night, presumably to avoid predators (Jenson 2001). Sand lance also display diurnal behavioral patterns, from dense foraging aggregations during daylight to less active benthic distributions at night. They appear to be visual predators and thus, in the absence of light, balance predation risk by seeking refuge (Hobson 1986). This balance is necessary as other predators (e.g. flatfish, whiting, haddock) aggregate near preferred sand lance bottom substrates as daylight diminishes and prey on them as they begin to burrow (Hobson 1986, Temming et al. 2004).
In the current study, the relative biomass of prey (presumably sand lance) was significantly higher in the top half of the water column during daylight hours than nighttime, and also in areas where humpback whales were surface feeding versus bottom feeding. However, the highest biomass of sand lance in the water column was found between 03:00 and 05:00 h, when sunlight is absent. If surface feeding by humpback whales is dictated solely by the presence of a threshold abundance of prey in the water column, we would expect the frequency of this behavior to closely mirror the timing of their prey in the upper portion of the water column. While we did observe limited surface feeding during these time periods, it was not at the high levels observed a few hours later, when sand lance density was lower, but more light was available. Our results suggest that surface feeding activities in humpback whales may be based at least in part on visual prey detection, as well as the presence of prey above a certain threshold abundance level in the water column. However, we were able to obtain only 2 tracks of 2 different individual whales during the pre-dawn and early morning period, so we acknowledge that a limited sample size could be biasing these results.

Our results complement those of Hazen et al. (2009), who show that humpback whales on Stellwagen Bank maximize their foraging efficiency when surface feeding by preferentially targeting dense, vertically oriented, larger aggregations of sand lance. We also acknowledge that in both studies we may not be accurately portraying the density of sand lance in the lower portion of the water column during bottom feeding, as an unknown portion of the sand lance may be indistinguishable from, or burrowed into, the bottom and therefore could not be detected using traditional fisheries echosounders. However, this further supports our hypothesis, as the added biomass would only increase the disproportionate amount of prey in the lower part of the water column during bottom feeding events.

Data regarding their diel feeding patterns provides important knowledge surrounding the means by which baleen whales locate prey and the behaviors used to maximize foraging efficiency. Unlike toothed 
whales, which use active echolocation to explore their environment and locate prey, baleen whales must rely largely on other sensory modes; however, the recent descriptions of low frequency echolocation-like calls (Stimpert et al. 2007) postulate a very limited ability to use echolocation. Our results suggest that surface feeding may have a significant visually based preylocating component. Presumed bottom feeding during our study occurred mostly in the absence of light and on prey buried in substrate, as hypothesized by Hain et al. (1995). Sand lance prefer sediment with medium-tocoarse sands, avoiding those with higher gravel or silt, clay and fine sand fractions (Wright et al. 2000, Jensen 2001). More detailed analysis of the mechanics of bottom feeding and areas where it occurs could reveal how humpback whales feed in and around the bottom, and if these are areas of high sand lance abundance (or habitat). At present, Hazen et al. (2009) provide a strong positive correlation between humpback whale feeding and substrate type (mud or sand not gravel) to support this avenue of thought.

Our observations took place in a single year when sand lance appeared to be abundant, but were made in similar locations to where Hain et al. (1995) made observations leading to their bottom-feeding hypothesis. Hence, we are unsure whether our findings can be generalized to other areas, other prey types, or even other years when prey may behave differently. For example, Ware et al. (2006) describe observations of humpback whale DTAG studies from the nearby Great South Channel in 2004, where tagged whales exhibited only bottom feeding, regardless of the time of day. Similar results were obtained in 2005 studies on nearby Jeffreys Ledge, where humpback whales were presumably feeding on herring and/or euphausiids (authors' unpubl. data). However, our findings of diurnal patterns are generally also supportive of those of Goodyear (1989), who also conducted tagging studies of feeding humpback whales on Stellwagen Bank during times of high sand lance abundance.

Humpback whales typically undergo seasonal migrations to wintering grounds where they fast while breeding, calving, and nursing. Thus, the large-scale distribution of baleen whales during the remainder of the year is necessarily related to areas of highly accessible prey. Humpback whales are more plastic in their feeding behaviors than many other baleen whales (Hain et al. 1982) and the diel patterns of feeding presented here are an example of this. Ecosystem variability in the ichthyofauna around Stellwagen Bank may have played a significant role in the adaptation of the apparent benthic feeding behaviors of humpback whales. Hain et al. (1995) suggest this, noting a coincident change in both the frequency of surface-observed feeding methods and the incidence of jaw scuffing (an indicator of bottom feeding), which occurred in times of low sand lance abundance.

Our results demonstrate the ability to conduct concurrent studies measuring both predator foraging behaviors and prey abundance and behavior using a combination of animal-borne tags and traditional fisheries acoustic methods. With these data, we show that individual whales can and do perform both surface and bottom feeding behaviors, switching from one to the other in relation to changing light and prey conditions. The results of this study add to our knowledge of humpback whale feeding behaviors and augment our understanding of how these predators adapt strategies to exploit prey, which, in turn, have adopted behaviors to avoid predation.

Acknowledgements. We are grateful to the officers and crew of the NOAA RV 'Nancy Foster' for their effort and support during field operations. Likewise, we are indebted to the members of the Gerry E. Studds Stellwagen Bank National Marine Sanctuary Office for their similar efforts. We also thank the other members of our field team for their consistent help and unmatched abilities. We thank the 4 anonymous reviewers who provided critical and valuable insights and suggestions. This research was carried out under MMPA Permit \#981-1707-01.

\section{LITERATURE CITED}

Acevedo-Gutiérrez A, Croll DA, Tershy BR (2002) High feeding costs limit dive time in the largest whales. J Exp Biol 205:1747-1753

Aoki K, Amano M, Yoshioka M, Mori K, Tokuda D, Miyazaki N (2007) Diel diving behavior of sperm whales off Japan. Mar Ecol Prog Ser 349:277-287

Croll DA, Acevedo-Gutiérrez A, Tershy BR, Urban-Ramirez J (2001) The diving behavior of blue and fin whales: Is dive duration shorter than expected based on oxygen stores. Comp Biochem Physiol A 129:797-809

> Demer D, Soule MA, Hewitt RP (1999) A multiple-frequency method for potentially improving the accuracy and precision of in situ target strength measurements. J Acoust Soc Am 105:2359-2376

Dolphin WF (1987) Prey densities and foraging of humpback whales, Megaptera novaeangliae. Experientia 43:468-471

Fogarty MJ, Cohen EB, Michaels WL, Morse WW (1991) Predation and the regulation of sand lance populations: an exploratory analysis. ICES J Mar Sci 193:120-124

Friedlaender AS, Halpin PN, Qian SS, Lawson GL, Wiebe PH, Thiele D, Read AJ (2006) Whale distribution in relation to prey abundance and oceanographic processes in shelf waters of the Western Antarctic Peninsula. Mar Ecol Prog Ser 317:297-310

Goldbogen DE, Calambokidis J, Croll DA, Harvey JT and others (2008) Foraging behavior of humpback whales: kimematic and respiratory patterns suggest a high cost for a lunge. J Exp Biol 211:3712-3719

Goldbogen JA, Calambokidis J, Shadwick RE, Oleson EM, McDonald MA, Hildebrand JA (2006) Kinematics of foraging dives and lunge-feeding in fin whales. J Exp Biol 209: 1231-1244

Goodyear JD (1989) Night behavior and ecology of humpback 
whales (Megaptera novaeangliae) in the western north Atlantic. MSc thesis, Moss Landing Marine Laboratories, San Jose State University, San Jose, CA

Hain JHW, Carter GR, Kraus SD, Mayo CA, Winn HE (1982) Feeding behavior of the humpback whale, Megaptera novaeangliae, in the western North Atlantic. Fish Bull (Wash DC) 80:259-268

Hain JHW, Ellis SL, Kenney RD, Clapham PJ, Gray BK, Weinrich MT, Babb IG (1995) Apparent bottom feeding by humpback whales on Stellwagen Bank. Mar Mamm Sci 11:464-479

Hazen E, Friedlaender AS, Thompson M, Ware C, Weinrich M, Halpin P, Wiley D (2009) Fine-scale prey aggregations and foraging ecology of humpback whales Megaptera novaeangliae. Mar Ecol Prog Ser 395:75-89

Hobson ES (1986) Predation on the Pacific sand lance, Ammodytes hexapterus, during the transition between day and night in southeastern Alaska. Copeia 1986: 223-226

Jensen H (2001) Settlement dynamics of the lesser sandeel Ammodytes marinus in the North Sea. PhD thesis, University of Aberdeen

Johnson MP, Tyack PL (2003) A digital acoustic recording tag for measuring the response of wild marine mammals to sound. IEEE J Oceanic Eng 28:3-12

Jurasz CM, Jurasz VP (1979) Feeding modes of the humpback whale, Megaptera novaeangliae, in southeast Alaska. Sci Rep Whales Res Inst 31:67-81

Kenney RD, Payne PM, Heinemann DW, Winn HE (1996) Shifts in northeast shelf cetacean distributions relative to trends in Gulf of Maine/Georges Bank finfish abundance. In: Sherman K, Jaworsk NA, Smayda TJ (eds) The Northeast Shelf ecosystem: Assessment, sustainability, and management. Blackwell Science, Cambridge, MA, p 169-196

Meyer TL, Cooper RA, Langston RW (1979) Relative abundance, behavior, and food habits of the American sand lance, Ammodytes americanus, from the Gulf of Maine. Fish Bull (Wash DC) 77:243-255

> Misund OA, Aglen A, Fronaes E (1995) Mapping the shape, size, and density of fish schools by echo integration and a high-resolution sonar. ICES J Mar Sci 52(1):11-20

Nowacek DP, Johnson MP, Tyack PL (2004) North Atlantic right whales (Eubalaena glacialis) ignore ships but respond to alerting stimuli. Proc R Soc Lond B Biol Sci 271:227-231

Overholtz WJ, Nicolas JR (1979) Apparent feeding by the fin whale, Balaenoptera physalus, and humpback whale, Megaptera novaeangliae, on the American sand lance, Ammodytes americanus, in the northwest Atlantic. Fish Bull (Wash DC) 77:285-287

Panigada S, Zanardelli M, Canese S, Jahoda M (1999) How deep can baleen whales dive? Mar Ecol Prog Ser 187: 309-311

Payne PM, Nicolas JR, O'Brien L, Powers KD (1986) The distribution of the humpback whale, Megaptera novaeangliae, on Georges Bank and in the Gulf of Maine in relation to densities of the sand eel, Ammodytes americanus.
Fish Bull (Wash DC) 84:271-277

Payne PM, Wiley DN, Young SB, Pittman S, Clapham PJ, Jossi JW (1990) Recent fluctuations in the abundance of baleen whales in the southern Gulf of Maine in relation to changes in selected prey. Fish Bull (Wash DC) 88:687-696

Piatt JF, Methven DA (1992) Threshold foraging behavior of baleen whales. Mar Ecol Prog Ser 84:205-210

Simard Y, Lavoie D (1999) The rich krill aggregation of the Sagenay-St. Lawrence Marine Park: hydroacoustic and geostatistical biomass estimates, structure, variability, and significance for whales. Can J Fish Aquat Sci 56: 1182-1197

Simila T, Ugarte F (1993) Surface and underwater observations of cooperatively feeding killer whales in northern Norway. Can J Zool 71:1494-1499

Stimpert AK, Wiley DN, Au WL, Johnson MP, Arsenault R (2007) 'Megapclicks': acoustic click trains and buzzes produced during night-time foraging of humpback whales (Megaptera novaeangliae). Biol Lett 3:467-470

Temming A, Gotz S, Mergardt N, Ehrich S (2004) Predation of whiting and haddock on sandeel: aggregative response, competition and diel periodicity. J Fish Biol 64:1351-1372

Ware C, Arsenault R, Plumlee M (2006) Visualizing the underwater behavior of humpback whales. IEEE Comput Graph Appl 26(4):14-18

> Weinrich MT, Schilling MR, Belt CR (1992) Evidence for acquisition of a novel feeding behavior: lobtail feeding in humpback whales, Megaptera novaeangliae. Anim Behav 44:1059-1072

Weinrich M, Martin M, Griffiths R, Bove J, Schilling M (1997) A shift in distribution of humpback whales, Megaptera novaeangliae, in response to prey in the southern Gulf of Maine. Fish Bull (Wash DC) 95:826-836

Whitehead H (1983) Structure and stability of humpback whale groups off Newfoundland. Can J Zool 61: 1391-1397

Whiten A, Ham R (1992) On the nature and evolution of imitation in the animal kingdom: reappraisal of a century of research. In: Slater PJB, Rosenblatt JS, Beer C, Milinski M (eds) Advances in the study of behavior. Academic Press, New York, p 239-283

> Winslade P (1974) Behavioral studies in the lesser sand eel Ammodytes marinus. I. The effect of food availability on activity and the role of olfaction on food detection. II. The effect of light intensity on activity. J Fish Biol 6:565-586

- Witteveen BH, Foy RJ, Wynne KM, Trembley Y (2008) Investigation of foraging habits and prey selection by humpback whales (Megaptera novaeangliae) using acoustic tags and concurrent fish surveys. Mar Mamm Sci 24: 516-534

> Woodward BL, Winn JP (2006) Apparent lateralized behavior in gray whales feeding off the central British Columbia coast. Mar Mamm Sci 22:64-73

> Wright PJ, Jensen H, Tuck I (2000) The influence of sediment type on the distribution of the lesser sand eel, Ammodytes marinus. J Sea Res 44:243-256

Zar JH (1996) Biostatistical analysis, 3rd edn. Prentice Hall, Upper Saddle River, NJ 